\title{
PAPILLARY SEROUS CYSTADENOFIBROMA OF PARATUBAL CYST WITH MASSIVE OEDEMA OF OVARY IN A TEENAGE GIRL - A CASE REPORT
}

Mamina Bhoi ${ }^{1}$, B.M. Sarvesh 2 , L. Lakshmana Rao ${ }^{3}$, Rehana Tippoo ${ }^{4}$, P. Viswanathan ${ }^{5}$

\section{HOW TO CITE THIS ARTICLE:}

Mamina Bhoi, BM Sarvesh, L Lakshmana Rao, Rehana Tippoo, P Viswanathan. "Papillary serous cystadenofibroma of paratubal cyst with massive oedema of ovary in a teenage girl - a case report". Journal of Evolution of Medical and Dental Sciences 2013; Vol. 2, Issue 40, October 07; Page: 7785-7789.

ABSTRACT: INTRODUCTION: Serous Cystadenofibroma is a benign, usually asymptomatic and a very rare tumour ${ }^{1}$ of fallopian tube. Massive oedema of ovary is not a neoplasm but is an interesting entity, grossly mimicking fibroma of ovary. CASE HISTORY: A fifteen year old girl presented with complaints of abdominal pain and vomiting since three days. She had history of irregular cycles since menarche (once in every six to seven months). Trans-abdominal sonography of the pelvis and Contrast Enhanced Computed Tomography (CECT), revealed Right Tubo-ovarian mass. Exploratory Laparotomy with Right partial salpingo-oophorectomy, and wedge biopsy of left ovary was done. The left ovary wedge biopsy tissue was taken for frozen section and later for hematoxylin and eosin sections. Frozen section showed only a fragment of ovarian stroma and a cyst wall lined by cuboidal to pseudo-stratified columnar epithelium. Histopathological diagnosis for the Right tubo-ovarian mass was confirmed as papillary serous cystadenofibroma of right paratubal cyst with haemorrhagic cyst and massive oedema of right ovary.

KEY-WORDS: Teenager, Fallopian tube, Cystadenofibroma - Paratubal cyst, Massive oedema of ovary.

INTRODUCTION: Serous Cystadenofibroma is a benign, usually asymptomatic and a very rare tumour ${ }^{1}$ of fallopian tube. Massive oedema of ovary is not a neoplasm but is an interesting entity, grossly mimicking fibroma of ovary. Benign epithelial tumours commonly encountered in the ovary are rare in fallopian tube. In the fallopian tube they most commonly arise in the ampullo-infundibular region. The most common benign epithelial tumour of the fallopian tube is the endometrioid polyp ${ }^{2,3}$, 4. Occasionally, adenomas or cyst-adenomas, papillomas and adenomyomas have been reported. Serous cystadenofibroma, an unusual tumour of the fallopian tube ${ }^{5,6}$ primarily occurring in the fimbria ${ }^{1,7}$ is considered to be of mullerian in origin ${ }^{3,4}$ with only 16 cases reported so far.

CASE HISTORY: A fifteen year old girl, presented with complaints of right iliac fossa pain and vomiting for past three days. She had history of irregular cycles since menarche (menstrual cycle once in every six to seven months). On examination the abdomen was soft. There was tenderness in the right iliac region. No organomegaly. Under strict aseptic precautions and combined anaesthesia, laparotomy was done. $30 \mathrm{ml}$ of straw coloured peritoneal fluid was found and was sent for fluid cytology. Right ovarian mass measuring $6 \times 4 \mathrm{~cm}$ identified, along with a Right para-ovarian mass measuring $8 \times 7 \mathrm{~cm}$ identified. Left ovary was polycystic. Wedge biopsy was taken from Left ovary and sent for frozen section and histopathological examination. Uterus was found to be normal Partial Right salpingo-oophorectomy was done and the excised specimens were sent for histopathological examination.

MACROSCOPY: Four specimens were received in separate containers. 


\section{CASE REPORT}

- Specimen1-Labelled as peritoneal fluid for fluid cytology: -Container had $5 \mathrm{ml}$ of haemorrhagic fluid- for fluid cytology.

- Specimen 2- Labelled as wedge biopsy of Left ovary- forfrozen section.

- Specimen 3- Labelled as Right Ovarian cyst:- Container had a single, grey black, grey brown, soft tissue mass measuring $8 \times 5 \times 2.5 \mathrm{~cm}$ [Figure 1 (a)]. Cut section- grey black, grey brown areas identified. Multiple small cysts identified each measuring around $0.5 \mathrm{~cm}$ in diameter [Figure 1 (b)].

- Specimen 4- Labelled as Right Fallopian tube- Container had a single, grey white, grey brown cystic mass measuring $6 \times 5.5 \times 2 \mathrm{~cm}$. Fimbriae was identified at one end of the specimen [Figure 2 (a)]. Cut section- grey brown grey black. Cyst wall was of uneven thickness [Figure 2 (b)].

FLUID CYTOLOGY: Multiple smears from the haemorrhagic peritoneal fluid stained with Giemsa revealed reactive mesothelial cells and degenerated lymphocytes against the proteinaceous and haemorrhagic background.

FROZEN SECTION: Left ovary frozen section showed fragments of ovarian stroma and a cyst wall lined by cuboidal to pseudo-stratified columnar epithelium while H\&E sections showed only ovarian stroma.

HISTOMORPHOLOGY: Multiple sections studied from the specimen labelled, Right Ovarian cyst stained with Haematoxylin and Eosin, revealed ovarian stroma along with a cystic lesion, the lining of which was replaced by fibro-vascular tissue and showed walthard cell rest [Figure 1 (c)]. The wall of the cyst as well as ovary showed marked oedema along with areas of haemorrhagic necrosis and congested blood vessels [Figure 1 (d) \& (e)]. Features were consistent with Massive Oedema of Ovary with a haemorrhagic cyst, and signs of torsion.

Multiple sections studied from the Right Fallopian tube with paratubal cyst revealed, Fallopian tube, with markedly congested blood vessels at the fimbrial end and Walthard cell nest [Figure 2 (c)].A paratubal cyst lined by low cuboidal to ciliated columnar cells was identified. Arising from the cyst was a lesion with histologic features consistent with papillary serous cystadenofibroma [Figure 2(d), (e) \& (f)]. Diagnosis of a papillary serous cystadenofibroma of right paratubal cyst with haemorrhagic cyst and massive oedema of right ovary was made.

DISCUSSION: Paratubal cysts are common incidental findings, rarely large enough to be clinically significant. They are usually of mullerian (paramesonephric) origin and are lined by a single layer of tubal-type ciliated epithelium. Some paratubal cysts are of mesothelial origin, and these are lined by flattened cells with surrounding fibrous or fatty tissue. Benign epithelial tumours are rare in fallopian tube. Serous adenofibromas, primarily encountered as incidental finding on microscopy in the fimbria are typically small, uncommon tumours. Most of these are considered to be benign mixed mullerian tumours analogous to the adenofibroma of the cervix and the serous cystadenofibroma of the ovary ${ }^{3,4}$. They are hard, white, predominantly solid fibromatous tumour, within which are small glands or cysts containing clear fluid and sometimes having polypoid excrescences, occasionally bilateral. In the present case, the tumour was a cystic lesion measuring $8 \times 5 \mathrm{~cm}$, with the cyst wall appearing black to 
brown, with multiple tiny polypoid projections.

In literature, four patients who had markedly enlarged ovaries were thought on clinical evaluation and at operation to be neoplasms, but were characterised on microscopical examination by diffuse oedema of the medulla and inner cortex ${ }^{9}$. These authors designated this lesion "massive oedema". Since their publication approximately 60 additional examples have been reported. The patients have ranged in age from 6-33 years, with an average of 21 years. Three-quarters of them have presented with abdominal pain, which may be acute and may be accompanied by abdominal swelling. In the remaining patients the clinical manifestations have been disorders of menstruation, evidence of androgen excess or both. Massive oedema of ovary ${ }^{9}, 10$ usually an entirely non-neoplastic proliferation, is rarely secondary to obstruction of lymphatic drainage by metastatic carcinoma ${ }^{8}$ and Meigs Syndrome. Ovarian enlargement is unilateral in $90 \%$ of cases. Partial or complete torsion of the involved ovary is present in at-least half the cases. The enlarged ovaries have ranged from $5.5-35 \mathrm{~cm}$ in diameter (average $11.5 \mathrm{~cm}$ ). Their outer surfaces are typically opaque and white; small follicle cysts may be seen beneath them. The sectioned surfaces characteristically have a watery appearance, resembling those of an oedematous fibroma or Krukenberg tumour, but identification of cystic follicles and sometimes corpora lutea within the oedematous tissue strongly suggests the diagnosis of massive oedema. Microscopic examination reveals oedematous, hypocellular stroma in the central portion of the ovary surrounding the follicles and their derivatives. In non-oedematous areas, the stroma may resemble normal stroma, hyperplastic stroma, or the type of stroma seen in ovarian fibromatosis. In 40\% cases luteinized stromal cells are present. Associated findings are dilatation of vascular and lymphatic channels. Rare foci of necrosis can be seen. The present case had similar clinical, operative and histopathological findings.

\section{REFERENCES:}

1. Bossuyt V, Medeiros F, Drapkin R, Folkins AK, Crum CP, Nucci MR. Adenofibroma of the fimbria: a common entity that is indistinguishable from ovarian adenofibroma. Int J Gynecol Pathol 2008, 27:390-397.

2. Green TH, Scully RE (1962). Tumors of the fallopian tube. Clin Obstet. Gynaecol, 5:888-906.

3. Kanbour AL, Burgers F, Salazar H (1973). Intramural adenofibroma of the fallopian tube; light and electron microscopy. Cancer, 31: 1433- 1439.

4. De La Fuente AA (1982). Benign mixed mullerian tumor - adenofibroma of the fallopian tube. Histopathol, 6: 661-666

5. Yesim G, Kacar SO (2003). Immunohistochemical profile of serous papillary cystadenofibroma of the fallopian tube: A clue of Paramesonephric origin. App. Immunohistochem. Mol. Morphol, 2: 153-155.

6. Zheng et al. Borderline papillary serous tumor of the fallopian tube. Am. J. Surg. Pathol1996; 20: 30-35.

7. Alvarado-Cabrero I, Navana SS, Young RH, et al. Tumours of the fimbriated end of the fallopian tube: a clinicopathologic analysis of 20 cases, including nine carcinomas. Int J Gynecol Pathol1997; 16:189-196.

8. Krasevic M, Haller H, Rupcic $S$, et al. Massive edema of the ovary: a report of two cases due to lymphatic permeation by metastatic carcinoma from the uterine cervix. Gynecol Oncol 2004; 93:564-567.

9. Kalstone CE, Jaffe RB, Abell mr. Massive edema of the ovary simulating fibroma. Obstet Gynecol 1969; 34:564-571.

10. Young RH, Scully RE. Fibromatosis and massive edema of ovary, possibly related entities: a 


\section{CASE REPORT}

report of 14 cases of fibromatosis and 11 cases of massive edema. Int J Gynecol Pathol 1984; 3:153-178.

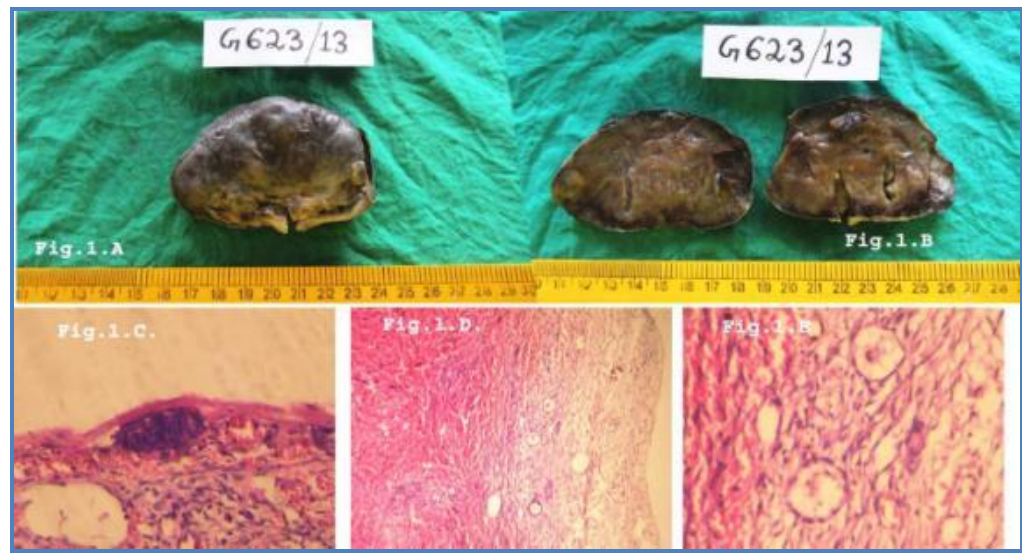

Figure 1(a):- Right Ovary: Grey black, grey brown, soft tissue mass measuring 8x5x2.5 cm.

Figure 1(b):- Cut Section: Watery in appearance. Grey black, grey brown areas identified. Multiple small cysts were identified each measuring around $0.5 \mathrm{~cm}$ in diameter.

Figure 1 (c), 4X, (d) - 10X \& (e) - 20X: Ovarian cortex along with a cystic lesion. Walthard cell nest was noted. The sub-cortical zone showed areas of haemorrhage. Entire tissue showed marked oedema along with areas of haemorrhagic necrosis, congested blood vessels and few follicles.

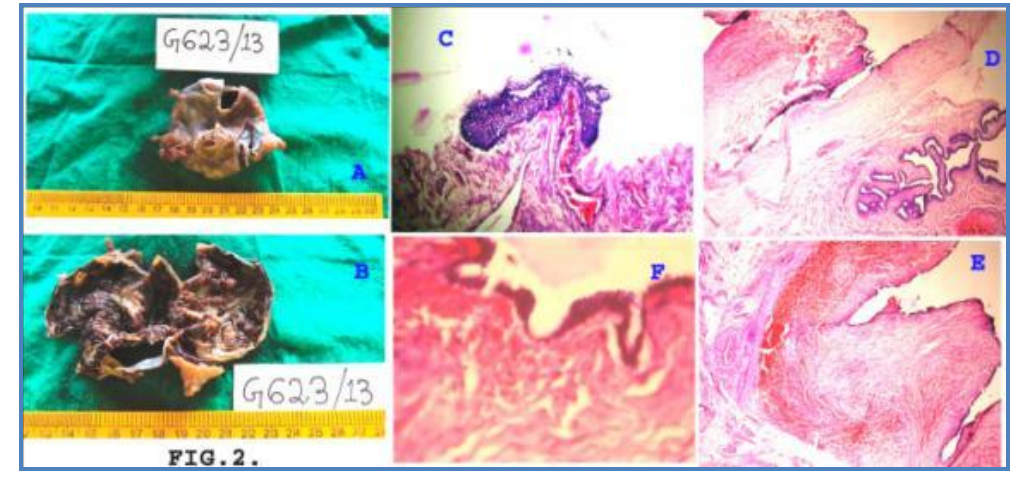

Figure 2 (a): Right Fallopian tube with a single grey white, grey brown cystic mass measuring $6 \times 5.5 \times 2 \mathrm{~cm}$. Fimbriae was identified at one end of the specimen.

Figure 2 (b): Cut section was grey brown, grey black. Cyst wall was of uneven thickness with multiple polypoid projections.

Figure 2 (c) - 20X: Walthard cell nest with congestion of paratubal cyst.

Figure 2 (d) \& (e) - 10X, (f) - 20X: Papillary serous cystadenofibroma of paratubal cyst lined by low cuboidal to ciliated columnar cells was identified beneath which spindle cells were present.

- All the microscopic pictures were taken using Nikon Cool pix Model 8400.

- X-Indicates the power of objective.

- Stain used - Hematoxylin and Eosin. 


\section{AUTHORS:}

1. Mamina Bhoi

2. B.M. Sarvesh

3. L. Lakshmana Rao

4. Rehana Tippoo

5. P. Viswanathan

\section{PARTICULARS OF CONTRIBUTORS:}

1. $3^{\text {rd }}$ Year Post Graduate, Department of Pathology, Rajah Muthiah Medical College, Annamalai University.

2. $3^{\text {rd }}$ Year Post Graduate, Department of Pathology, Rajah Muthiah Medical College, Annamalai University.

3. Professor and Head, Department of Pathology, Rajah Muthiah Medical College, Annamalai University.

4. Professor, Department of Pathology, Rajah Muthiah Medical College, Annamalai University.
5. Professor, Department of Pathology, Rajah Muthiah Medical College, Annamalai University.

\section{NAME ADDRESS EMAIL ID OF THE CORRESPONDING AUTHOR:}

Dr. P. Viswanathan,

Professor,

Department of Pathology,

Faculty of Medicine,

Rajah Muthiah Medical College,

Annamalai University, Chidambaram,

Tamilnadu, India, Pin - 608002.

Email - drpviswanathan1@gmail.com

Date of Submission: 18/09/2013.

Date of Peer Review: 19/09/2013.

Date of Acceptance: 01/10/2013.

Date of Publishing: 07/10/2013 